УДК 339.138

JEL M31; M37

Конкс Виктор Янович

канд. физ.-мат. наук, ФГБОУ ВО

«Государственный университет управления»,

г. Москва, Российская Федерация

ORCID: 0000-0002-6161-6947

e-mail:9997114@mail.ru

Краснов Евгений Владимирович канд. экон. наук, ФГБОУ ВО «Государственный университет управления», г. Москва, Российская Федерация

e-mail:ev_krasnov@guu.ru

Сумарокова Екатерина Викторовна канд. экон. наук, ФГБОУ ВО «Государственный университет управления», г. Москва, Российская Федерация

ORCID: 0000-0001-8963-6774

e-mail: sumarokova@bk.ru

\section{Konks Viktor}

Candidate of Physical and Mathematical Sciences, State University of Managament, Moscow, Russia

ORCID: 0000-0002-6161-6947

e-mail:9997114@mail.ru

\section{Krasnov Evgenii}

Candidate of Econimic Sciences, State

University of Managament, Moscow, Russia

e-mail:ev_krasnov@guu.ru

\section{Sumarokova Ekaterina}

Candidate of Economic Sciences, State

University of Managament, Moscow, Russia

ORCID: 0000-0001-8963-6774

e-mail: sumarokova@bk.ru

\section{ЦИФРОВЫЕ ТЕХНОЛОГИИ МАРКЕТИНГА И ПРОДАЖ: ВIG DАТА И ЭФФЕКТ СИНЕРГИИ}

\begin{abstract}
Аннотация. В настоящеее время многие российские компании успешно решают задачу привлечения значительного количества клиентских требований и запросов на продажи и обслуживание. Как следствие, возникает проблема соответствия возможностей компании по удовлетворению заявленных сервисов и их уровня, резервирования излишних мощностей и ресурсов компании, что приводит к уменьшению прибыли. В статье, на основе теории массового обслуживания, рассмотрено применение новых способов измерения, достижения и поддержания эффективности бизнеса, приводящих к повышению его эластичности и маневренности, так как эффективность бизнеса оченивается через сравнение собранных данных, существующих показателей, бухгалтерских балансов или ключевых показателей эффективности.
\end{abstract}

Ключевые слова: оптимизация бизнес-прочессов, теория очередей, система массового обслуживания, циифровые технологии.

Цитирование: Конкс В.Я., Краснов Е.В., Сумарокова Е.В. Цифровые технологии маркетинга и продаж: big data и эффект синергии//Вестник университета. 2019. № 8. С. 46-54.

\section{DIGITAL MARKETING AND SALES TECHNOLOGIES: BIG DATA AND SYNERGY EFFECT}

Annotation. Currently, many Russian companies successfully solve the problem of attracting a significant number of customer requirements and requests for sales and service. As a result, there is a problem of matching the company's capabilities to meet the declared services and their level, reserving excess capacity and resources of the company, which leads to a decrease in profits. The article is based on the queuing theory and considers the application of new ways to measure, achieve and maintain the efficiency of the business, leading to an increase in its elasticity and maneuverability, as the efficiency of the business is measured by comparing the collected data, existing indicators, balance sheets or key performance indicators.

Keywords: optimization of business processes, queue theory, queuing system, digital technologies.

For citation: Konks V,Ya., Krasnov E.V., Sumarokova E.V. Digital marketing and sales technologies: big data and synergy effect (2019) Vestnik universiteta, I. 8, pp. 46-54. doi: 10.26425/1816-42772019-8-46-54

Оптимизация бизнес-процессов предприятия является системным подходом, который замещает ресурсоемкие усилия и улучшения. Оптимизация бизнес-процессов направлена на инновации и получение более высоких результатов. Для этого необходима полная смена бизнес-процессов, а не постепенное их совершенствование. Улучшение бизнес-процессов позволяют выдерживать структурные изменения в организации, которые необходимы при внедрении новых технологий [5].

Гибкость бизнеса определяется как коллективные возможности и конструкции, позволяющие постоянно трансформировать бизнес для достижения своих результатов и прогнозировать гибкость, отзывчивость и инициативы во времена перемен и неопределенности. Оптимизация бизнес-процессов делает это возможным, акцентируясь на эффективности бизнеса, в котором маневренность бизнеса - это не только то, что вы делаете, но и то, во что вы превращаетесь.

Факторы, влияющие на эффективность бизнеса и на его маневренность - разные. Некоторые из этих факторов можно поставить под контроль и мониторинг с правильным измерением и интерпретацией событий. Эти факторы включают микросреду бизнеса: сеть организаций, включая партнеров, поставщиков, клиентов, государственных учреждений или дистрибьюторов, занимающихся поставкой товаров и услуг через конкуренцию

(C) Конкс В.Я., Краснов Е.В., Сумарокова Е.В., 2019. Статья доступна по лицензии Creative Commons «Attribution» («Атрибуция») 4.0. всемирная (http://creativecommons.org/licenses/by/4.0/).

The Author(s), 2019. This is an open access article under the CC BY 4.0 license (http://creativecommons.org/licenses/by/4.0/).

(c) (i) 
и сотрудничество, где каждый в какой-то степени является участником. Макросреда включает политику, правила и законы, регулирующие отношения поставщиков и потребителей.

Окружающая среда, рынок, законодательство, развиваются и варьируются в зависимости от сил внутри бизнеса. Среда, в которой значимое событие произошло или происходит, обеспечивает фон и условия, которые будут использоваться при оценке политики и правил в качестве основы принятия корректирующих действий для бизнес-процессов и услуг [1]. Это сочетание факторов и систем обеспечения (процессы, информация, события, правила, содержание, аналитика, сотрудничество и мониторинг), на которое влияет оптимизация бизнес-процессов.

Для повышения уровня эффективности бизнеса необходимо увеличить его гибкость, устойчивость и обеспечить непрерывное улучшение. Возможные решения:

- изменение действующей модели со скоростью, стоимостью, качеством и предсказуемостью в соответствии с перспективными потребностями;

- отслеживание в реальном времени происходящих в бизнесе событий с использованием новых информационных технологий;

- обеспечение возможностей корректировки или организационных изменений для поддержания необходимого уровня результатов;

- оптимизация процесса изменений;

- понимание и контроль в режиме реального времени для улучшения процесса принятия решений.

1. Модель оптимального обслуживания, или модель теории очередей, используется для определения оптимального числа каналов обслуживания по отношению к потребности в них. К ситуациям, в которых модель теории очередей может быть полезна, следует отнести звонки людей в авиакомпанию для резервирования места и получения информации, ожидание в очереди на техническое обслуживание автомобиля, мастеров по ремонту оборудования, очередь грузовиков под разгрузку на склад, ожидание клиентами банка свободного кассира.

Если, например, клиентам приходится слишком долго ждать кассира, они могут решить перенести свои счета в другой банк. Таким образом, принципиальная проблема заключается в уравновешивании расходов на дополнительные каналы обслуживания и потерь от обслуживания на уровне ниже оптимального.

Основная причина недостатка в каналах обслуживания заключается в краткосрочных изменениях частоты обращения потребителей за обслуживанием, а также времени обслуживания. Это ведет к избыточной пропускной способности в определенные моменты времени и появлению очередей в другие, хотя пропускная способность могла бы быть достаточной, если бы осуществлялся полный контроль за поступлением требований и можно было бы построить соответствующий график. Модель теории очередей снабжает руководство инструментом определения оптимального числа каналов обслуживания, которые необходимо иметь, чтобы сбалансировать издержки в случаях чрезмерно малого и чрезмерно большого их количества.

Подобные решения основываются, в том числе и на экономическом анализе, который содержит все методы оценки издержек и экономических выгод, а также относительной рентабельности деятельности предприятия. Типичная задача поиска сбалансированного решения основана на анализе безубыточности, методе принятия решений с определением точки, в которой общий доход уравнивается суммарными издержками точка, после прохождения которой, предприятие становится прибыльным.

2. Теория массового обслуживания. Система массового обслуживания (далее - СМО) может быть двух видов: с ожиданием и без ожидания (то есть, с потерями). В первом случае вызов (требование, заявка), пришедший в колл-центр в момент, когда занята нужная линия, остается ждать момента соединения. Во втором случае он «покидает систему» и не требует внимания СМО [3; 4].

Основы знаний о линиях обслуживания, часто называемые теорией очередей - ценный инструмент операционного менеджера. Линии обслуживания являются общим понятием; это могут, например, быть автомобили, ожидающие ремонта в центре автосервиса, или это очередь печатных работ, скомплектованная в заказ на печать, или студенты, ожидающие консультации профессора. Как линейное программирование и прогнозирование служат моделями, применяемыми в широком диапазоне операционных решений, так и модели теории очередей успешно используются в производственной области и секторе сервиса. Анализ очередей в терминах длин очереди, среднего времени ожидания и других факторов помогает нам установить сервисные системы (такие, как колл-центры), организовать деятельность по обслуживанию и деятельность по контролю. 
Операционным менеджерам требуется знать точку равновесия между затратами, требуемыми для хорошего сервиса, и затратами времени на обслуживание покупателей или машин. Менеджеры хотят иметь очереди настолько короткие, чтобы покупатели не были недовольны, когда покупатели или не делают покупку, или покупают, но потом не возвращаются. Таким образом, менеджеры стремятся к такому ожиданию, которое представляло бы баланс для значительных сбережений в затратах на сервис.

3. Возможные решения. До конца 2014 г. в автобизнесе в РФ дилерские предприятия росли, развивались, боролись за лучшие сегменты автомобильного рынка и за увеличение его доли. Вкладывали средства в развитие бизнеса, техническое оснащение, обслуживание клиентов и их привлечение. Переживали периодический рост и падение спроса на автомобили и сопутствующие услуги. Определялись среди участников бизнеса аутсайдеры и лидеры. Случился кризис, повлекший за собой обесценивание рубля вдвое. Потерявшие покой граждане вспомнили навыки советского периода в истории страны и кинулись покупать автомобили, чтобы как-то сохранить свои средства. Количество покупателей многократно выросло и оказалось, что дилерские предприятия не в состоянии удовлетворить массовый спрос. Их архаичные принципы и методы работы, во многом копировавшие худшие примеры административно-государственных структур, не рассматривали потребителя как главное действующее лицо. Дилерские предприятия не были гибкими, отзывчивыми и инициативными во времена перемен и неопределенности. О маневренности не было и речи не только из-за нежелания, но и по причинам определенной специфики продукта и бизнеса.

Ажиотажный спрос 2014 г. закончился затяжным падением спроса 2015 г. Наступило время перемен и улучшений в дилерских предприятиях, переживших потрясения. Возможности привлечения клиентов, которые и до кризиса были достаточно масштабны, дополнили всевозможными решениями по коммуникациям, обслуживанию и удержанию. Лучшими дилерскими предприятиями стали широко внедряться цифровые технологии [2; 6]. Такие программные продукты как Callkeeper (технология сохранения данных клиентской интернет-заявки для выполнения обратного звонка). Она следит за посетителем сайта и выбирает подходящее время, чтобы предложить звонок, предлагает позвонить за 26 с, сообщение интригует - клиент оставляет номер и ждет звонка. Как только клиент ввел номер, система звонит и соединяет вызов с клиентом. Calltouch и Calltracking сделали возможным постоянное отслеживание взаимодействия сотрудников с клиентом.

Calltouch - комплексное аналитическое решение, система сквозной аналитики, колл-трекинга и управления рекламой, которое позволяет, исследуя тренды и закономерности, выявить скрытые механизмы продаж и повысить отдачу от рекламы. Каждый посетитель, который находится на сайте, на котором установлен CallTouch, связывается с уникальным номером телефона. В тот момент, когда пользователь звонит по этому номеру, CallTouch получает информацию о том, откуда пришел на сайт позвонивший пользователь (источник, рекламная кампания, ключевой запрос и прочее). Данные по звонкам собираются в личном кабинете и представляются клиенту в аналитических отчетах.

Колл-трекинг (англ. call-tracking - отслеживание звонков) - технология определения рекламных источников, с которых приходят звонки клиентов. Статический колл-трекинг - привязка одного номера телефона к одному рекламному источнику. Например, реклама в журнале. Динамический колл-трекинг - технология подмены и показа определенного номера каждому уникальному посетителю сайта. Такой тип колл-трекинга позволяет отслеживать рекламный источник с точностью до поисковой фразы, а контекстную рекламу - до конкретного объявления.

Стало обычным для руководителей подразделений подключаться к процессу взаимодействия с клиентом в любой необходимый момент времени для внесения коррекции и помощи. Контроль качества работы сотрудников стало возможным документировать. Накапливать и обрабатывать статистику по каждому клиенту и сотруднику. Стало возможным осуществлять управление (планирование, организация, координация, мотивация и контроль) во всей возможной полноте.

4. Как компания «РОЛЬФ» оптимизировала рекламные кампании. Польза коллтрекинга в интернет-маркетинге, несмотря на молодость сервиса, уже не подвергается сомнению. И хотя технология пока ясна не всем, она прозрачна, удобна и эффективна в использовании. Пример качественного кейса по этому направлению раскрывает суть сервиса на опыте компании «РОЛЬФ». Сначала компания пришла к решению начать использование цифровых технологий в одном маленьком дилерском центре, а затем присоединились все остальные дилеры компании. У каждого из них разные потребности, но дилеров объединяет одна задача - нужны звонки и заявки от потенциальных клиентов. Каждый из дилерских центров решает ее по-своему: кто-то старается 
улучшить качество звонков, кто-то - снизить их стоимость, а кто-то работает над привлечением на сайт заинтересованной аудитории. Практика показала, что лучше всего для достижения этих целей подходит СРА-модель (англ. Cost Per Action, при такой системе работы оплачиваются только определенные действия пользователей на сайте рекламодателя), которая невозможна без колл-трекинга. Выбор СРА-модели повлиял и на рекламную стратегию компании. К примеру, решили полностью отказаться от медийного размещения, определив его неэффективность. Оценка показала, что стоимость приводимого контакта с этих источников в 3-4 раза превышает стоимость контакта, пришедшего с контекста. Кроме того, после установки колл-трекинг-сервиса Calltouch достигнуты следующие результаты.

1. Скорректирована рекламная стратегия, исходя из примеров, которые открылись в процессе аналитики. Некоторые запросы, традиционно считавшиеся самыми конверсионными, на деле такими не являются. Яркий пример - брендовый запрос компании, за который идет борьба в контексте. Оказалось, стоимость звонка с такого запроса в десятки раз превышает ожидаемую. Корректируя стратегию, пришлось согласиться, что звонок стоимостью 30 тыс. рублей, при среднерыночной стоимости около 1 000-1500 рублей, не нужен.

2. Снижены затраты за счет проведенных экспериментов по перераспределению текстов и посадочных страниц. Когда становилось понятно, что запрос эффективный и работает на других брендах, были изменены тексты, чтобы не тратить деньги на привлечение аудитории, которую не интересуют предложения рекламодателя. Также были изменены посадочные страницы, когда возникала вероятность, что пользователь не находит на сайте то, что ищет и именно поэтому уходит.

В интернет-маркетинге посадочная страница (англ. landing page) - единичная веб-страница, которая возникает при клике на ссылку из поисковой выдачи или рекламу в интернете. Обыкновенно посадочная страница является логичным продолжением рекламы, поискового результата или ссылки. С точки зрения владельца сайта, это такая страница, которая мотивирует пользователя к совершению определенного действия за предельно краткий период времени, то есть по принципу «здесь и сейчас».

3. Выстроена эффективная рекламная стратегия на основе данных колл-трекинга о поведении пользователей. Например, оказалось, что посетители сайтов зачастую не обращают внимания на часы работы компании. Несмотря на то, что многие дилерские центры открыты до 24 ч., после 21 ч. звонки практически прекращаются, хотя клиенты продолжают оставлять заявки на сайтах. Такая информация, была использована на практике и вечернюю работу сосредоточили именно на обработке онлайн-заявок.

4. Проанализировано поведение пользователей на сайте до совершения звонка. Было интересно, как клиенты компании выбирают бренд. Оказалось, посетитель более чем готов менять свое решение в процессе выбора автомобиля и редко привязан только к одному варианту: «Я хочу только эту машину и никакую другую». Например, человек может прийти на сайт дилера через кампанию одного бренда, скажем, Honda, a потом начать смотреть Mitsubishi совсем другого класса. Так он просматривает многие предложения, а завершает сессию новостью о каком-нибудь самом дешевом кроссовере. В итоге при звонке дилеру выясняется, что этот пользователь выбирает машину классом выше, не самой простой комплектации и берет ее в кредит.

Подобное исследование было опубликовано компанией Google: его специалисты пришли к выводу, что покупатель в среднем 8 раз меняет свое решение в процессе выбора автомобиля и в 80 \% случаев приобретает не ту машину, с которой начинал поиски. Зная такую особенность поведения пользователей, можно ненавязчиво, с помощью партнерских сетей, ретаргетинга, привлечь их внимание и к другим предложениям дилера.

5. Определено, в какое время чаще всего звонят пользователи и какие звонки нужно считать конверсионными.

В среднем ежедневно поступает около 40-50 звонков на одного дилера и один бренд. Самые активные дни - понедельник и вторник. Зимой к ним добавляются еще и выходные. Но летом суббота «мертвый день» - поступает не более 10-20 звонков, зато в сам дилерский центр приезжает больше клиентов. В среднем целевым звонком считается тот, который длился более 1 мин. Но этот параметр зависит от конкретного дилерского центра. Есть дилеры, у которых соединение длится по 15 с, а есть те, кто соединяет практически сразу. Поэтому иногда и 40 с звонка бывает достаточно - за это время человек успевает выяснить интересующую его информацию, уведомить дилера о своем визите и оставить контакты. Были такие случаи, когда при прослушивании нецелевых звонков выяснялось, что беседа была продуктивной, и дилерский центр получил контактные данные потенциального клиента. 
Благодаря Calltouch сэкономлены деньги клиентов и улучшены показатели работы, снижена стоимость контактов и увеличено их количество. Стало понятным, какие запросы и направления интересны с точки зрения стоимости контакта, а в какие вкладывать бюджеты - пустое занятие.

Рассмотрим, как это работает на практике.

1. В компании «РОЛЬФ» считают, что в автобизнесе преувеличено значение трафика. Сам по себе трафик в компании генерируется в более, чем достаточном количестве. Гораздо важнее, насколько сильна связка между отделами маркетинга и продаж, насколько глубоко знают они работу друг друга и говорят ли на одном digital-языке.

\section{Таблица 1}

Эффективность. Данные роста автомобильного рынка и компании «РОЛЬФ»

\begin{tabular}{|l|c|c|c|c|}
\hline \multicolumn{1}{|c|}{ Категория } & $\mathbf{2 0 1 3}$ г. & $\mathbf{2 0 1 4}$ г. & $\mathbf{2 0 1 5}$ г. & $\mathbf{2 0 1 6}$ г. \\
\hline Рынок, \% & $-1,9$ & $-9,1$ & $-38,2$ & $-13,3$ \\
РОЛЬФ, \% & $+18,2$ & $+14,4$ & $-31,9$ & $+17,1$ \\
\hline
\end{tabular}

Источник:

2. Взаимодействие классическое: руководитель отдела продаж и бренд-менеджер. Руководитель ставит задачи по трафику для бренд-менеджера. Бренд-менеджер обеспечивает заданные контрольные цифры. Руководитель отдела продаж обеспечивает продажи по текущему трафику. Контрольные цифры выполняются в необходимом количестве. Их распределение по времени и моделям такое, как есть. В компании считают, что существенным, если не самым главным, является качество трафика, а руководитель отдела продаж и бренд-менеджер ставят общие цели:

- трафик;

- количество штук розницы;

- кумулятивная маржа.

Для руководителей и подчиненных отдела продаж и отдела маркетинга КРІ формируются с учетом выполнения этих трех показателей.

3. Обучение специалистов. Компания «Яндекс» проводит специальные дни совместного обучения специалистов и руководителей отдела продаж и отдела маркетинга всех желающих автомобильных дилеров, так называемые Digital Day, после которых они начинают говорить на «одном языке». Специалисты из «Яндекс» подробно разъясняют проблематику создания контекста на сайте, стоимость поддержания коммуникаций в Интернете, их эффективности и окупаемости.

4. Уровень компетенций. Концепция компании в уровнях требований к бренд-менеджерам и руководителям отдела продаж условно может быть проиллюстрирована в процентах. Знание бренда бренд-менеджерами $100 \%$, руководителями отдела продаж - $100 \%$; технологии продаж бренд-менеджерами - $100 \%$, руководителями отдела продаж - $100 \%$; маркетинга, интернет-технологии бренд-менеджерами - $200 \%$, руководителями отдела продаж - $90 \%$; ситуации в смежных отделах бренд-менеджерами -70 \%, руководителями отдела продаж - $100 \%$; командной работы на результат бренд менеджерами - 200 \%, руководителями отдела продаж - 200 \%. При этом к бренд-менеджерам нет требования по умению завершить сделку с клиентом, если потребуется, это сфера руководителей отдела продаж. Но в остальном овладение смежными профессиями у бренд-менеджеров и руководителей отдела продаж практически полное. Бренд-менеджер должен уметь прослушивать записанные телефонные переговоры продавца-консультанта, понимать насколько конверсионным каждый из них был вначале и насколько конверсионным он был в конце. Поэтому бренд-менеджеры по уровню подготовки - готовые старшие продавцы-консультанты. Естественно, что свое собственное профессиональное направление бренд-менеджеры должны знать не на 100 \%, а на «200 \%». Руководители отдела продаж должны знать о маркетинге практически все. Ситуация в смежных отделах должна быть для руководителей отдела продаж и бренд-менеджеров известна на соответствующем уровне. В такой ситуации можно говорить об очень высоком уровне командной работы руководителей отдела продаж и бренд-менеджеров на результат («200 \%»). Возможен эффект синергии. 
5. Общая модель взаимодействия бренд-менеджеров и руководителей отдела продаж на месяц.

1. План по штукам и марже. - 2. План по трафику. - 3. Генерация трафика. -4 . Обработка трафика. -5. Продажи. - 6. Контрольные КРI. - 7. Продажи (допродажи).

6. КРІ. Маркетинг.

- критерий чистоты трафика, KPI - более 50 \% чистого трафика, Вес - 5;

- mix трафика, отношение визитов к звонкам, КРІ - выше $1 / 6$, Вес - 5;

- соответствие количества трафика выставленному плану на месяц, КРІ - план выполнен, Вес - 10 .

Каждый руководитель отдела продаж, старшие продавцы-консультанты, руководители отдела продаж финансовых услуг, руководители отдела продаж автомобилей с пробегом, бренд менеджеры, собираются не реже одного раза в месяц под руководством директора по маркетингу компании на оценку текущего трафика по текущему месяцу. Рассматривают пункты 1-3, указанные выше. Чистота трафика: клиент может совершить несколько входящих звонков, в разные дилерские центры компании. Соответственно цифры трафика больше, а продажа потенциально одна. Таким образом, учитывается в трафике номер телефона клиента, появившийся впервые. Определено опытным путем количество трафика - mix (смешанного - чистого и нет), приходящегося на один первичный визит по каждой модели и марке автомобилей, продаваемых в компании. Плановый показатель эффективности (Strike-Rate, далее - SR) визита всегда существенно выше SR звонка. Оценивается KPI по пунктам 1-3. Участники встреч могут определить по этим KPI в каком месте, в какой ситуации с планом они находятся.

7. KPI. Статистика визитов. Ручное распределение трафика по группе продавцов-консультантов, согласно персональным SR. Бывает, что продавец-консультант очень хорошо говорит по телефону, но визитов у него по звонкам недостаточно и, соответственно, у него недостаточное количество заключенных контрактов. Бывает, что продавец-консультант лучше заключает контракты из визитов или лучше заключает контракты из звонков. Соответственно, руководитель отдела продаж должен этих продавцов-консультантов очень хорошо знать. Если в какой-нибудь день намечается какая-либо маркетинговая активность, то на звонки надо «сажать» тех продавцов-консультантов, у которых лучший показатель по отработке этих звонков. Если продавец-консультант хорошо отрабатывает визиты, то его надо «сажать» на мероприятия, например, «Ночи продаж», «Дни открытых дверей» и прочие. За показателями эффективности продавцовконсультантов необходимо следить очень тщательно, так как «неправильный» продавец-консультант, или на «неправильном» месте может принести больше вреда, чем пользы.

Каждый продавец-консультант и отдел продаж в целом в компании оценивается по проценту квалификации. В компании проводится 100 \% прослушивание всех телефонных звонков и иных коммуникаций по новым автомобилям, по автомобилям с пробегом, trade in, по пролонгации, по сервису. Каждый звонок, после того, как он состоялся, не позднее, чем через 3 минуты прослушивается сотрудниками специальной группы телемаркетинга и этому звонку выставляется оценка. Первая задача, которая решается - это то, что они сразу понимают, взят ли контакт у клиента и назначена ли встреча с этим клиентом. Если встреча не назначена, на рабочем столе старшего продавца-консультанта и/или руководителя отдела продаж появляется информационное сообщение о том, что вот этот конкретный звонок требует немедленной отработки руководителем. Руководитель должен в течение 20 мин. сделать звонок этому клиенту и сказать - «Уважаемый И. И., я все-таки хочу еще раз Вас пригласить, коль скоро это не получилось у моего продавца консультанта. Я вас лично жду» - и, таким образом, компания доназначает до 60 \% встреч по звонкам, которые требуют такой отработки. Вторая задача. Если накапливается статистика, что по одному и тому же продавцу-консультанту в течение какого-то короткого промежутка времени выпадает много таких рабочих листов, и он не берет контакты и не назначает встречи в достаточном количестве, тот отстраняется от приема трафика и далее идут определенные плановые мероприятия с этим продавцом-консультантом.

По каждому виду активности есть плановый SR визита по звонку, то есть, какое количество визитов должно быть назначено со 100 звонков. Этот КРI тоже тщательно отслеживается, поскольку он является вторым качественным показателем качества трафика.

Итак, есть два качественных показателя: квалификация продавца-консультанта и визиты по звонкам, которые уже фактически состоялись. Если после звонка состоялся визит, это значит, что клиент реально хочет купить автомобиль и готов на этом этапе инвестировать в это свое время. А значит, нельзя говорить о том, что трафик был некачественный. 
Если нет визита после звонка, вопросы к трафику есть, вопросы к бренд-менеджерам и по всему маркетингу в целом. Анализируются SR контракта от «звонка» и SR контракта от «салона». Соответственно, каждый отдел продаж, каждый продавец-консультант имеет свои собственные показатели плановые, которые они должны выполнять с точки зрения конкретного трафика в конкретном периоде времени.

8. Одновременное использование различных современных инструментов, технологий и программных продуктов. По результатам оценки доли рынка, компания увеличила долю кликов (на свои посадочные страницы), приходящихся на нее из общего количества в сегменте интернет-провайдера («Яндекс») с $15 \%$ до 18-20\%, и соответственно трафика, при этом не увеличивая расходов по продвижению. Рассмотрим, как этого достичь.

Компания использует все возможные системы метрические, которые стоят на посадочных страницах компании, это Calltouch, CallKeeper, call-tracking, CoMagic, CALLBACK HUNTER, Google Analitics, Яндекс Метрика.

Например, Calltouch, использование которого на рынке продвигается не столь активно и широко в силу определенного консерватизма потенциальных пользователей. Сохранилось стремление к использованию «красивых» телефонных номеров, на которые были потрачены иногда значительные средства. И теперь связаться с компанией можно только по этому легко узнаваемому номеру. Использование подменных номеров Calltouch приводит к тому, что компания знает точно об эффективности каждой рекламной акции, каждого своего запроса. Иногда компания использует более 1000 подменных номеров ежедневно, и не несет никаких потерь от того, что люди не запоминают номеров, поскольку им дается столько полиграфических материалов в момент выдачи автомобиля, в момент встречи в салоне, что если они хотят дозвониться в компанию, они всегда могут это сделать. А без подменных номеров невозможно понять, из-за очень большого объема обращений, как все работает, так как отсутствие легкой, доступной связи не дает адекватной картины клиентской реакции.

Другой пример, CallKeeper. В свое время, когда в компании научились генерировать интернет-заявки и получали на 1000 звонков 800 интернет-заявок, казалось, что это отличный результат. Пока не выяснилось, что при среднем SR около $10 \%$ конверсии в продажи по клиентским звонкам, конверсия в продажи по интернет-заявкам - около 1 \%. Причина в том, что продавцы-консультанты не могут работать на высоком уровне по исходящим контактам в режиме «холодных звонков». А интернет-заявка, это в любом случае инициативный звонок продавца-консультанта. Для того, чтобы снять психологическую проблему «холодного звонка» в компании установлен CallKeeper с системой обратного звонка. Клиент по факту заполняет ту же самую интернет-заявку, но как только он ее отправляет, система сама начинает автоматический дозвон оператору. Оператор, в свою очередь, дозванивается до клиента и соединяет его с продавцом-консультантом. Это фактически интернет-заявка, но продавец-консультант об этом не знает, для него это обычный звонок. Соответственно, для продавца-консультанта SR по этим заявкам поднялся до того же уровня, что и при работе с обычными звонками. Это серьезно снизило маркетинговые затраты на единицу выдачи.

Собственная система накопления и обработки данных, разработанная компанией, действует для всех направлений продаж, сервиса, всех вспомогательных подразделений, всех дилерских центров компании. В ней хранятся все данные о клиентах, сотрудниках, коммуникациях, бизнес-процессах компании. Руководители маркетинга и продаж имеют возможность извлекать из нее все, что им необходимо, любого рода аналитику, статистику, показатели и результаты операционной деятельности в режиме реального времени.

9. Синергия знаний о клиенте. Файл совмещенных данных о клиенте, работающем с ним продавце консультанте и всей информации, связанной с ними, истории отношений и использованных инструментов и аналитики:

- «звонок» - внешние данные, Google Analitics, метрика, calltouch, callkeeper;

- рабочий лист - внутренние данные, статус клиента, стоимость контакта, эффективность работы продавца консультанта, эффективность подрядчика

Известно из накопленной информации, сколько компании стоит каждый конкретный клиент. Не средняя стоимость звонка, которая тоже, конечно, интересует или средняя стоимость выдачи. Известно, сколько стоит выдача конкретному клиенту, сколько стоит «Out» (расторгнутый контракт) конкретного клиента, если он не «отработан» и «Out» каждого клиента. Это очень полезные знания. Поскольку иногда, особенно если в компанию приходят новые сотрудники, которые пока не видели таких цифр, и им показывают стоимость их дня, 
стоимость звонка, стоимость «Out», это становится для них неожиданностью. И когда имеются персональные данные о расходах на них вчера, сегодня и завтра, они получают полезную и адекватную оценку, это помогает им видеть реальную картину. Они учатся выстраивать свою работу и линию поведения должным образом.

10. Чистота трафика:

- «звонок»/визит - «новый клиент», «посещает тот же дилерский центр», «посещает несколько дилерских центров компании»;

- текущий статус трафика - «в работе», «перспектива», «out», «контракт», «выдан автомобиль».

Для компании важно, чтобы чистота трафика соответствовала требованиям (KPI, более 50 \% трафика должно быть чистым). Ценен первый визит, так как, чем больше он «двигается» в том же дилерском центре, в нескольких дилерских центрах, тем дороже он обходится компании, поскольку «покупает» компания его в каждом дилерском центре.

Отдельно о клиентах со статусом «Out». Компания получает около 45 тыс. звонков ежемесячно, из них 35 тыс. по новым автомобилям и 10 тыс. по автомобилям с пробегом. У продавцов-консультантов отсутствует понятие дефицита трафика и уход потенциального клиента не создает большой проблемы, придут другие. Клиентов со статусом «Out» много, причины разные - не сошлись в цене, не устраивают модели и пр.

Проанализируем, что компания делает с такими клиентами. Они не покидают позицию потенциального клиента, такой статус конкретно только для этого дилерского центра. Когда определенный отдела продаж закончил работу с этим клиентом, этот статус фиксируется в системе. На следующее утро этот контакт доступен для любого дилерского центра компании, для руководителя отдела продаж, который хочет с ним работать. Соответственно, дилерский центр с утра забирает необходимое количество клиентов со статусом «Out» по определенным моделям, определенным брендам, с которыми дилерский центр привык работать и имеет опыт заключения контрактов по такому продукту и такому запросу. Каждый руководитель отдела продаж видит в системе, сколько его клиентов со статусом «Out» поменяли статус на «контракт заключен» в других дилерских центрах и сколько чужих клиентов со статусом «Out» поменяли статус на «контракт заключен» в их дилерском центре.

Любопытно, что в среде специалистов по продажам возник дух соперничества по достижению высоких показателей по возврату клиентов со статусом «Out». Прозрачность существующей системы позволяет следить за процессом всем участникам в режиме реального времени. В дополнение к удовольствию чувствовать себя профессионалом высокого класса, учитываются результаты работы продавцов-консультантов, руководителей отдела продаж, дилерских центров по показателям, влияющим на материальное поощрение и карьеру. Кроме того, параллельно группа телемаркетинга занимается возвратом клиентов со статусом «Out», которые не были по каким-либо причинам востребованы руководителями отделов продаж или продавцами консультантами, в статус «контракт заключен» наравне с руководителями отделов продаж и продавцами-консультантами. Специалисты группы телемаркетинга, отлично владеющие всей информацией о возможностях компании, предлагают и информируют клиента о тех, о которых он, возможно, еще не знает. Группа телемаркетинга, таким образом, возвращает клиентов, особенно премиальных брендов, где маржа наибольшая. Полугодовая статистика 2016 г. таких возвратов показала около 30 проданных автомобилей в месяц, суммарно по всему холдингу. В связи с этим было принято решение использовать подобный подход и в массовом сегменте, и штат группы телемаркетинга был увеличен кратно.

11. Big Data. В компании работают около 8200 сотрудников. Компания осуществляет продажи автомобилей ассортимента, обеспеченного 23 мировыми брендами. В компанию входит 62 дилерских центра. Нарастающим итогом компания продала более 1,1 млн новых автомобилей и более 213 тыс. автомобилей с пробегом. В компании в год проводится около 1500 маркетинговых активностей.

Руководители продаж и маркетинга, руководители компании должны держать под контролем и эффективно управлять бизнес-процессами с большими базами данных. Это более 1,3 млн файлов клиентов с историей, купивших автомобили, сотни тысяч контактов, рабочих листов потенциальных клиентов с разными статусами, тысячи файлов с историями сотрудников, архивных данных и так далее.

Все это невозможно было бы реализовать без собственной ЕRP-системы (Enterprise Resource Planning система), которая создана и постоянно модернизируется специалистами компании в соответствии с потребностями бизнеса. Enterprise Resource Planning система предназначена для управления всей совокупностью ресурсов компании: денежными средствами, производственными мощностями, персоналом и т. д. 
Основное предназначение систем класса ERP - обеспечение единого информационного поля для всех инфраструктурных единиц предприятия и предоставление полной всеобъемлющей достоверной информации для принятия управленческих решений. При этом архитектурно вся модель ERP-системы предприятия может быть реализована как на одном едином комплексе (программном приложении), так на совокупности нескольких систем, интегрированных между собой.

В ней реализован ряд инноваций, которых нет ни в одном из существующих на рынке типовых решений. Не случайно ERP-систему компании рассматривают как прототип информационной системы предприятий автомобильного бизнеса многие импортеры.

Внедрять новые технологии и совершенствовать взаимодействие с клиентом очень трудно и затратно. Колебания спроса заставляют наращивать количество обслуживающего персонала, чтобы быть готовым обслужить максимальное число обращений. Множество других проблем приходится решать руководителям предприятий. Одно из возможных решений - интегрированный маркетинг, когда каждый сотрудник работает с полной отдачей, многие владеют смежными специальностями, руководитель каждого уровня участвует и помогает в работе подчиненным. Одним словом - все члены единой команды, нацелены на успех общего дела, за счет чего гарантировано возникает эффект синергии при условии применения рассмотренных в статье цифровых технологий.

\section{Библиография}

1. Азоев, Г. Л., Алешникова, В. И., Токарев, Б. Е. и др. Маркетинг: освоение профессии. Учебник для вузов / Под редакцией Г. Л. Азоева. - СПб.: ООО Издательство «Питер», 2018. - 543 с.

2. Статкус, А. В., Бутковская, Г. В. Цифровой маркетинг: поведение потребителей//Вестник университета. - 2019. - № 5. C. $5-11$.

3. Ивченко, Г. И., Каштанов, В. А., Коваленко, И. Н. Теория массового обслуживания. - 2-е изд., испр. и доб. - М.: Либроком, 2012.

4. Рыков, В. В., Козырев, Д. В. Основы теории массового обслуживания. - М.: ИНФРА-М, 2019.

5. Долганова, О. И., Виноградова, Е. В., Лобанова, А. М. Моделирование бизнес-процессов: учебник и практикум для академического бакалавриата. - М.: Юрайт, 2017.

6. Конкс, В. Я., Сумарокова, Е. В. Искусственный интеллект и цифровые технологии в автомобильном транспорте//В сборнике: Шаг в будущее: искусственный интеллект и цифровая экономика. Революция в управлении: новая цифровая экономика или новый мир машин. Материалы II Международного научного форума, 2018. - С.467-473.

\section{References}

1. Azoev G. L., Aleshnikova V. I., Tokarev B. E. [et al]. Marketing: osvoenie professii. Uchebnik dlya vuzov [Marketing: mastering the profession. University textbook], SPb.: OOO Izdatelstvo «Piter», 2018, $543 \mathrm{p}$.

2. Statkus A. V., Butkovskaya G. V. Tsifrovoi marketing: povedenie potrebitelei [Digital marketing: consumer behavior], Vestnik Universiteta, 2019, I. 5, pp. 5-11.

3. Ivchenko G. I., Kashtanov V. A., Kovalenko I. N. Teoriya massovogo obsluzhivaniya [Queuing theory], 2-ye izd., ispr. i dob., Moscow, Librokom, 2012.

4. Rykov V. V., Kozyrev D. V. Osnovy teorii massovogo obsluzhivaniya [The basics of queuing theory]. Moscow, INFRA-M, 2019.

5. Dolganova O. I., Vinogradova Ye. V., Lobanova A. M. Modelirovanie biznes-protsessov: uchebnik i praktikum dlya akademicheskogo bakalavriata [Business Process Modeling: A Textbook and Workshop for Academic Baccalaureate], pod red. O. I. Dolganovoi. Moscow, Yurait, 2017.

6. Konks V. Ya., Sumarokova Ye. V. Iskusstvennyi intellekt i tsifrovye tekhnologii v avtomobil'nom transporte [Artificial intelligence and digital technologies in automobile transport], V sbornike: Shag v budushchee: iskusstvennyi intellekt i tsifrovaya ekonomika. Revolyutsiya v upravlenii: novaya tsifrovaya ekonomika ili novyi mir mashin. Materialy II Mezhdunarodnogo nauchnogo foruma [Proceedings of the II International Scientific Forum: "Step into the future: artificial intelligence and the digital economy. A revolution in management: a new digital economy or a new world of machines"], 2018, pp. 467-473. 